\title{
A Case Study Exploring the Use of Virtual Reality in the Zoo Context
}

\author{
Zsuzsa Lugosi* and Phyllis C. Lee
}

Division of Psychology, Faculty of Natural Sciences, University of Stirling

*Corresponding author (Email: zsuzsa.lugosi.sci@gmail.com)

Citation - Lugosi, Z., \& Lee, P. C. (2021). A case study exploring the use of virtual reality in the zoo context. Animal Behavior and Cognition, 8(4), 576-588. https://doi.org/10.26451/abc.08.04.09.2021

\begin{abstract}
Virtual Reality (VR) is now a popular tool in education and for engagement with the natural world, but to date little research has investigated its potential in a zoo setting. We aimed to gauge the interest of the visiting public in using VR technology at Royal Zoological Society of Scotland's (RZSS) Edinburgh Zoo. A VR $(n=12)$ and a video condition $(n=12$ ), both introducing the lives and conservation concerns of African wild dogs (Lycaon pictus), were used to gain greater insight of the thoughts and perceptions of how individuals evaluated a purposebuilt VR experience and to enable comparisons of learning outcomes for both technologies. We used semistructured interviews; responses were evaluated through thematic analysis and descriptive analysis. Younger participants (aged 13-18 years) emphasized that VR allowed them close and personal access to the animals. Adult participants (aged 19 and above) pointed out the entertainment value of the VR experience while highlighting the potential of its educational aspect; that of enabling visitors to see animals in their natural habitat. While our results require further confirmation due to the limited sample size and restricted circumstances of data collection, we suggest that VR could be usefully introduced as a public education and visitor engagement tool that would benefit the visitors' learning and overall experience at the zoo.
\end{abstract}

Keywords - Zoo education, Immersive technology, Virtual reality, Visitor-animal interactions

Zoos are highly popular visitor attractions, with an estimated 700 million visits to zoos and aquaria around the world every year (Gusset \& Dick, 2010; WAZA, 2017). While providing exhibits and amenities that attract and entertain visitors (Godinez \& Fernandez, 2019), zoos also aim to fulfil roles of conservation, facilitate scientific research and educate the public about the importance of their activities (Carr \& Cohen, 2011; Roe et al., 2014). As a part of educational efforts, zoos often offer live animal demonstrations of behavior or activities (e.g., feeding, training). These are popular events with more than $25 \%$ of visitors attending such "shows" (Spooner et al., 2021). The majority of zoos worldwide also provide experiences that allow visitors to have close encounters with animals (e.g., petting or feeding animals, and drive or walk-through exhibits; D'Cruze et al., 2019), which are potential sources of additional income for the zoo and simultaneously provide a profound experience to the visitor (Luebke \& Matiasek, 2013). The fact that these close encounters are available indicates that there is desire for direct visitor-zoo animal experiences. However, there are a number of ethical issues to resolve before and after these experiences, as discussed by Learmonths (2020), including disease transmission, stress, aggression, and negative welfare of the animals. For a recent discussion on visitor-animal interactions and the implication of these, see Sherwen and Hemsworth (2019).

VR might be optimal to provide safe and enjoyable close encounters without ethical compromises. Recent work by Carter et al. (2020) highlighted that using VR to provide 'backstage' 
insight into the care of little penguins (Eudyptula minor) created positive attitudes not only towards the species but the zoo also. It is not yet known how VR could promote positive interactions between zoohoused animals and visitors, and therefore it is worth exploring how it could be used in the future to encourage positive visitor behaviors.

Virtual Reality is a simulated experience, using computer-generated images (CGI), real life images or videos, played to a recipient on a head mounted device (HMD) that transmits audio and visual stimuli. Those using the VR can have varying degrees of freedom to manipulate their surroundings, which may affect the quality of that experience; in simpler 360-degree experiences, viewers can only observe, albeit with full rotation. There are also more complex experiences where viewers have the opportunity to move objects around or change their location within the experience. There are many applications to VR; it can be used to teach pupils molecular biology when it is essential that students visualize the material in three dimensions (Tan \& Waugh, 2013); it has been used for decades to teach medical students skills such as keyhole surgery (Ota et al., 1995). Markowitz and colleagues (2018) took high school, college students and adults on a virtual field trip to learn about ocean acidification and climate change in a series of studies of VR effectiveness on perspective-taking and attitude change. Participants could either be "corals" or "divers" exploring a coral reef. Positive knowledge gain and an increasingly positive attitude towards nature resulted from all VR experiences (Markowitz et al., 2018). Ahn and colleagues (2016) found that taking the perspective of animals in immersive virtual environments led to a stronger sense of interconnectedness with nature. Lamb and colleagues (2018) compared four conditions of learning (video lectures, Serious Educational Games, VR and hands-on activities) to investigate differences in brain activity during these tasks. VR was shown to engage the parts of the brain responsible for critical thinking; these same parts of the brain were also activated during hands-on activities (Lamb et al., 2018). These studies suggest that VR has the potential to create naturalistic environments that can facilitate learning, actions and attitudes similar to those resulting from hands-on activities and experiences.

The use of VR as an educational tool for zoos was first explored in the late 1990s at Zoo Atlanta (Georgia, USA) with their 'Virtual Reality gorilla exhibit' (Allison et al., 1997). The purpose of that immersive virtual environment was to encourage middle school students to learn about gorillas, their social structure, vocalizations and habitat. Allison et al.'s (1997) investigation was focused on the technological aspects of VR and they only described student reactions anecdotally, prompting further investigations of its educational and entertainment value. A number of zoos around the world have now started using VR technology in the absence of assessments of their lasting value; for example, Taronga Zoo (Sydney, Australia) offers Google Expedition experiences of their zoo. Guangdong Zoo (China) transformed a section of their zoo into a hall that has virtual and augmented reality technologies to engage the visitors. RZSS Edinburgh Zoo uses hand held VR devices to supplement their education sessions with school groups.

Researchers have also been exploring the potential of using VR to investigate aspects of cognition with primates (Dolins et al., 2017). This line of investigation has provided insights into how using such technology can be enriching for the animals; considering their restricted environments, VR could allow for more exploration and potentially interaction with other species in a safe virtual space. Coe and Hoy (2020) suggested that such technology could be used to provide a platform for animal-visitor interactions at zoos. While this idea needs further scrutiny, it should be considered as a possible mechanism to enrich the lives and wellbeing of both the animals living in human care and the visitors seeking to connect with them.

The present study set out to explore how VR might fit into zoo visitors' experience. We aimed to compare VR's educational and entertainment properties with those of videos, which are traditionally a part of the zoo experience. Our hypotheses were that learning about the species would be improved by delivery via VR (better retention of more diverse knowledge) and that the experience would be more enjoyable than its equivalent in video format. 


\section{Method}

RZSS Edinburgh Zoo was identified as an optimum institution to carry out the study because it is a major conservation and education visitor attraction in Scotland. African wild dogs were chosen as subjects as, during project planning, there was a small wild dog pack at Edinburgh Zoo and the company that created the VR experience (Reality Garage) had access to film of wild dogs living in a reserve in South Africa. By the time the study was conducted, the wild dog pack from Edinburgh Zoo had been moved to another facility, although the zoo was still known by many visitors for having a wild dog exhibit.

\section{Video Experience}

A 3 min-40 s video was created for the purpose of this research, featuring African wild dogs (Lycaon pictus). This video explained basic behavioral traits and conservation concerns of the animals in the narration (see supplementary material). The video was created with Adobe Premier Pro and footage was used from the streaming website, YouTube. The footage showed wild dogs hunting in a pack, resting, and interacting with other species; it also showed humans laying traps and altering the landscape, to highlight the impact of these activities on the species. The video was shown on a Clevertouch Plus Interactive Screen.

\section{VR Experience}

A 4 min-16 s-VR experience was created by and is owned by Reality Garage (Colorado, USA). It presented footage of African wild dogs in a semi-wild environment, occasionally featuring other animals naturally occurring in the same habitat. Wild dogs were seen interacting with each other and feeding; the footage was also altered at points to highlight differences between captive and natural environments; a city landscape was included to highlight the human impact on the species. The experience was narrated although this was less detailed than that used than in the video condition (see supplementary material). The hardware for showing the VR experience was an Oculus Go Standalone 32 GB VR Headset.

\section{Participants}

Overall, 24 people participated in our study. In the video condition, they were separated into two age groups (see Figure 1): adults above the age of 19 years $(n=6, M=40.7$ years, $S D=18.9)$ and children between the ages of 13 and 18 years $(n=6, M=14.5$ years, $S D=1.5)$. Participants for the VR condition were separated into the same two age groups: adults $(n=6, M=25.5$ years, $S D=6.7)$ and children $(n=6, M=17.3$ years, $S D=0.8)$.

Data for seven participants aged 13-19 years were collected outside the zoo environment as the younger participant group proved difficult to contact at the zoo during school terms. Data for both conditions were collected this way. Before participation, all these participants confirmed that they had been to Edinburgh Zoo in the past two years. Participants were not asked to disclose their gender to avoid possible interviewer bias about gender and VR experiences (e.g., Annetta et al., 2009). Although participants were not asked if they were native English speakers, it was confirmed that they were comfortable enough with English to complete the interview process. 
Figure 1

Average Age of Participants in the VR and Video Conditions

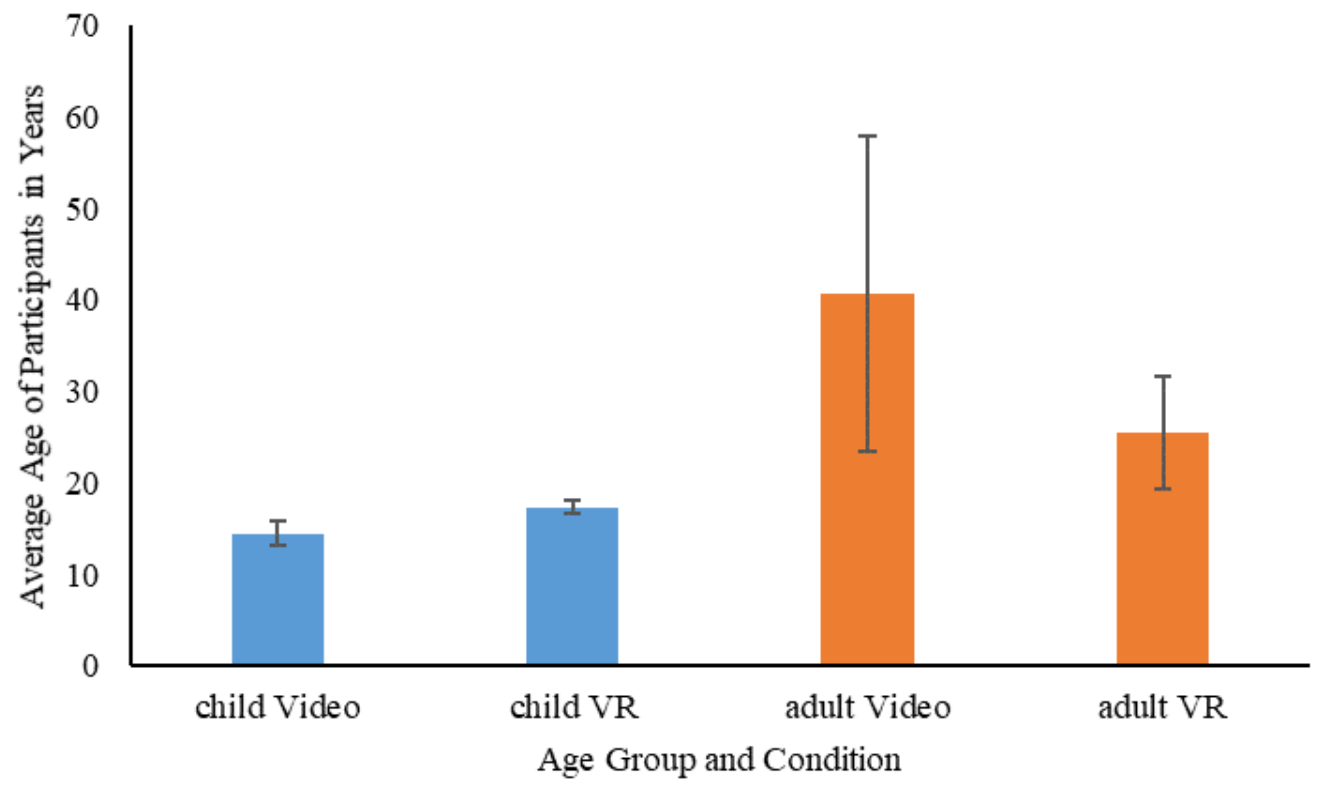

Note. Error bars represent standard deviation.

\section{Procedure}

Participants of a variety of ages were opportunistically approached during their visit to the zoo at the area in front of the Learning and Discovery Centre. As participants were not incentivized for taking part in the study, many visitors refused to take part. If visitors showed interest in participating in the study, they were taken to a room inside the center where they would watch the video or the VR experience, after which the lead researcher would conduct a short interview with them. Participant and parental consent was given before the interviews started. Participants were allocated to the VR experience or the control video condition randomly. Both the video and the VR experience were less than 5 min long and the follow-up interview typically lasted around 4 to $8 \mathrm{~min}$. Semi-structured interviews were used as this method enables a focused structure between the interviewee and the interviewer, while allowing flexibility for the interviewer to expand on the conversation if necessary (Kallio et al., 2016). We used purpose-built questions (see interview script in supplementary material) in which we asked questions to measure knowledge retention about the species and their conservation status. We also asked participants if they liked the experience that they had watched and whether they wanted to elaborate on their answers.

Knowledge retention was assessed via the following two questions: "Based on the experience/video you have just watched, how would you describe African wild dogs?" and "From the experience/video can you recall any of the conservation issues facing African wild dogs?" Responses $(n=$ 24) were quantified based on criteria detailed in Table 1. We also explored how much participants enjoyed the experience by asking: "Did you enjoy the experience/video? If yes, what were the best features of it? If not, could you tell me in more details why?" The diverse set of participant responses were analyzed via thematic analysis. 
Table 1

Questions and Criteria for Coding of the Qualitative Responses

\begin{tabular}{|c|c|c|}
\hline Theme and question & Yes, if answer mentions: & No, if answer mentions: \\
\hline $\begin{array}{l}\text { Information recall about species } \\
\text { Based on the experience/video you have just } \\
\text { watched, how would you describe African wild } \\
\text { dogs? }\end{array}$ & $\begin{array}{l}\text { Physical characteristics, home range, } \\
\text { social structure, diet (included in the } \\
\text { narration) }\end{array}$ & $\begin{array}{l}\text { Wild animal, cute, physical } \\
\text { characteristics only }\end{array}$ \\
\hline $\begin{array}{l}\text { Information recall about conservation issues } \\
\text { From the experience/video can you recall any of the } \\
\text { conservation issues facing African wild dogs? }\end{array}$ & $\begin{array}{l}\text { Human-wild dog conflict, disease } \\
\text { transmission, habitat loss (included in } \\
\text { the narration) }\end{array}$ & $\begin{array}{l}\text { Humans, in incorrect context } \\
\text { (e.g., zoo) }\end{array}$ \\
\hline $\begin{array}{l}\text { Enjoyability } \\
\text { Did you enjoy the experience/video? } \\
\text { If yes, what were the best features of it? } \\
\text { If not, could you tell me in more details why? }\end{array}$ & Yes, exciting, interesting, enjoyable & $\begin{array}{l}\text { No, boring, not interesting, } \\
\text { could not take it all in }\end{array}$ \\
\hline $\begin{array}{l}\text { Informative } \\
\text { Did you enjoy the experience/video? } \\
\text { If yes, what were the best features of it? } \\
\text { If not, could you tell me in more details why? }\end{array}$ & $\begin{array}{l}\text { Learning new information, thought } \\
\text { provoking experience, informative, } \\
\text { detailed information }\end{array}$ & $\begin{array}{l}\text { Did not learn anything new, } \\
\text { was not interested in learning } \\
\text { anything new }\end{array}$ \\
\hline $\begin{array}{l}\text { Naturalistic } \\
\text { Did you enjoy the experience/video? } \\
\text { If yes, what were the best features of it? } \\
\text { If not, could you tell me in more details why? }\end{array}$ & $\begin{array}{l}\text { Enjoy seeing animals in natural } \\
\text { environment, performing natural } \\
\text { behavior, wild animal compared to zoo } \\
\text { animal }\end{array}$ & $\begin{array}{l}\text { Did not find closeness of } \\
\text { animal interesting, } \\
\text { preference to see animal in } \\
\text { zoo }\end{array}$ \\
\hline
\end{tabular}

Once participants completed the interview, they were given an information sheet that included their participant ID. Once interviews were completed, participants were thanked for their cooperation and were shown where to exit the building.

Participants who were not recruited at Edinburgh Zoo were students at Wallace High School (Stirling, Scotland). They were recruited and interviewed at a local board gaming store (Common Ground Games, Stirling) as this location allowed for direct contact and gathering parental consent. The interviews followed the same procedure as detailed above and all participants confirmed that they had previously visited the zoo.

Interviews were recorded with a dictaphone (Olympus Digital Voice Recorder, VN-541PC) and were transcribed with the use of an online software, Trint (Otrint.com). Interviews were conducted between April and June of 2019, both on weekdays and weekends in the Learning and Discovery Centre at Edinburgh Zoo (Edinburgh, UK) and at Common Ground Games (Stirling, UK).

Ethical approval for the study was granted under post-graduate research conditions by the University of Stirling General Ethical Committee, via the Psychology Ethics Review Panel. Permission was also given by the RZSS ethics / education committee.

\section{Analysis}

The interviews were transcribed in the seven days following the recording; however, there was a 3-week cooling-off period between transcription of all interviews and the start of the thematic analysis to ensure impartial analysis. We used thematic coding of the transcripts from the discussions centered on the experiences of either the video-only or the VR groups of participants. Thematic analysis allowed us to identify patterns in the collected qualitative data. This was done by following the six steps outlined by Braun and Clarke (2006): data familiarization, coding, generating initial themes, reviewing themes, defining and naming themes and writing up the results. To counterbalance the probability of coding bias, a research assistant independently analyzed the interviews from the video condition for the 19+ age 
group. The researcher and the second coder did similar, but not identical, themes (see Table S1 in supplementary material). We derived and use here three main replicable themes: Information retrieval (subthemes: accurate recall about wild dogs, accurate recall about conservation, inaccurate recall and no recall), impact of experience (subthemes: enjoyable, informative, naturalistic) and purpose of technology. The second coder determined four main themes with no subtheme division: Information about wild dogs (T1), information about conservation (T2), eye opener about the species (T3) and learning technology at the zoo (T4). T1 and T2 were agreed as matching the subthemes under information retrieval while T3 is similar to our naturalistic subtheme. T4 matched the purpose of technology theme.

Descriptive analysis was carried out to display group averages (adults vs children, VR vs video). Participant answers were coded for the analysis based on the questions and criteria in relation to the kind of responses as set out in Table 1 .

\section{Results}

\section{Theme One: Information Retrieval}

The first theme of information retrieval illustrates that in both conditions, participants were able to recall information about both African wild dogs' lifestyle and the conservation issues highlighted in the experiences (Figure 2; for examples of the theme see Table 2). Child participants in the VR condition, however, were on average 3 years older than those in the video condition and this may have influenced their ability to retain and recall information.

\section{Figure 2}

Summary of 'Information Retrieval' Theme by Responses

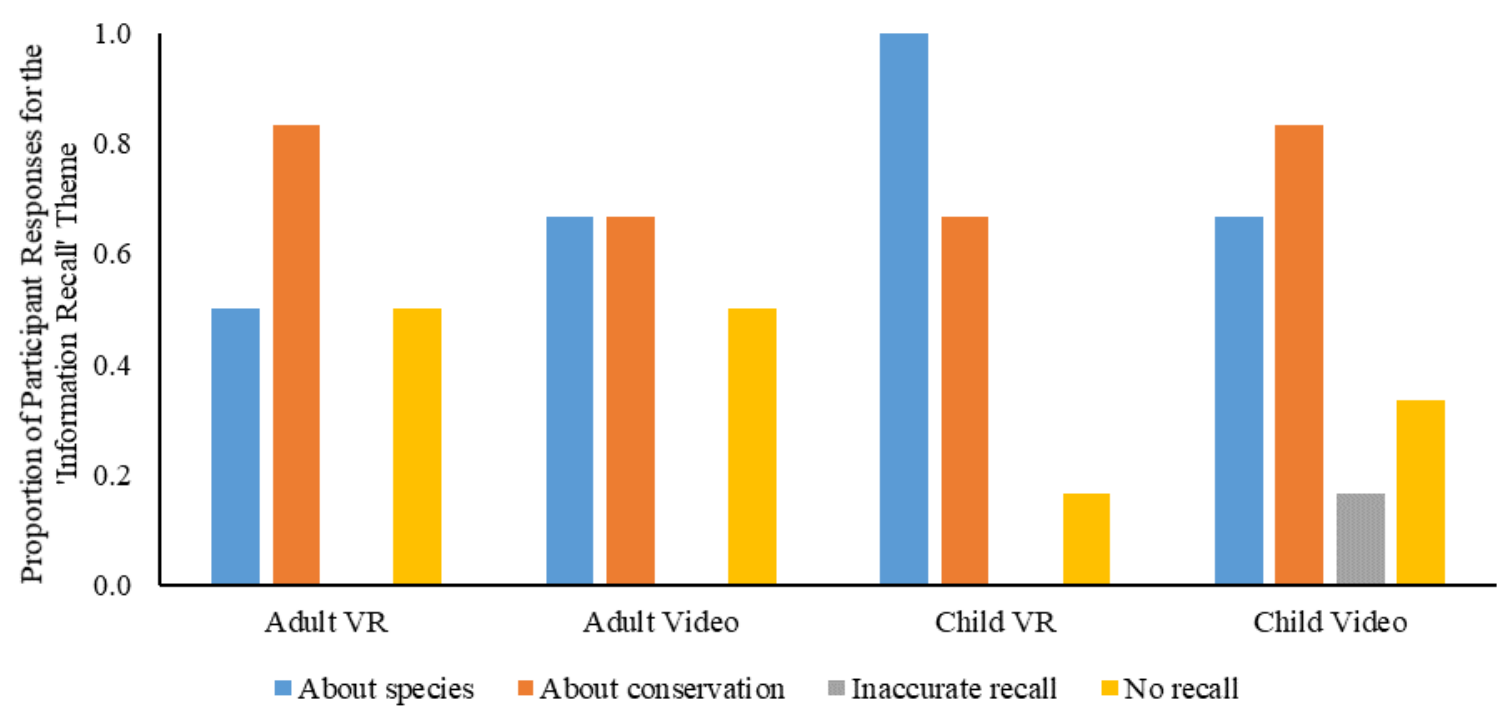

The first two subthemes (accurate recall about the species and about their conservation) did not reveal any marked differences between the conditions; in both the VR and the video conditions, participants could recall the main body of information mentioned in the narrative.

The third subtheme (inaccurate recall) disclosed an interesting phenomenon in the younger age group. The narration mentioned: "Some carnivorous animals occasionally supplement their diet with fruits, grass or scavenging on dead animals; but wild dogs only eat fresh kill." This information was later recalled by a participant in the video condition as "...some of them might change to fruit and grass...". This is still a striking error of recall for the video condition participants. Both the VR experience and the 
video showed a vivid feeding scene of the wild dogs, highlighting their exclusively carnivorous diet visually.

Compared to the younger age group, adults did not have inaccurate recall when answering the interview questions. Instead, adults were more likely to say they could not remember (no information recall) or recall specific information. In the VR condition, this was explained by the immersive effect of the experience itself.

\section{Table 2}

Examples of the 'Information Retrieval' Theme

\begin{tabular}{|c|c|c|}
\hline Subthemes & VR experience & Video-only experience \\
\hline $\begin{array}{l}\text { Accurate recall about } \\
\text { wild dogs }\end{array}$ & $\begin{array}{l}\text { Child } \\
\text { "Obviously I heard about that kind of thing, pack } \\
\text { hunting and how they got the leaders but the } \\
\text { African dogs, they have female leaders..." } \\
\text { Adult } \\
\text { "They live in a group, hunt together and females } \\
\text { are the boss of the pack." }\end{array}$ & $\begin{array}{l}\text { Child } \\
\text { "live in pack of 3-30." } \\
\text { "they (humans) keep killing them because of } \\
\text { their livestock." } \\
\text { Adult } \\
\text { "...they are meat eaters, they are good at } \\
\text { looking after each other..." }\end{array}$ \\
\hline $\begin{array}{l}\text { Accurate recall about } \\
\text { conservation }\end{array}$ & $\begin{array}{l}\text { Child } \\
\text { "A lot of their (wild dog territory) land is being } \\
\text { taken away for cities and farmland. And. When } \\
\text { they tried to hunt on farmland they are killed by } \\
\text { the farmers" } \\
\text { Adult } \\
\text { "They have an issue with humans taking over their } \\
\text { territory and also humans killing predators like } \\
\text { wild dogs for taking their livestock." }\end{array}$ & $\begin{array}{l}\text { Child } \\
\text { "People digging them up. The ground up. } \\
\text { (Participant referring to habitat destruction) } \\
\text { Diseases from domesticated dogs." } \\
\frac{\text { Adult }}{\text { "Habitat loss because of humans." }}\end{array}$ \\
\hline $\begin{array}{l}\text { Inaccurate recall- } \\
\text { Child only }\end{array}$ & & "...sometimes like live on fruit and crops." \\
\hline $\begin{array}{l}\text { No information } \\
\text { retrieval- } \\
\text { Adult only }\end{array}$ & $\begin{array}{l}\text { "Well, I wasn't really listening, I was more looking } \\
\text { at them." }\end{array}$ & $\begin{array}{l}\text { "No." (Participant could not recall information } \\
\text { when asked about conservation issues facing } \\
\text { African wild dogs.) }\end{array}$ \\
\hline
\end{tabular}

\section{Theme Two: Impact of Experience}

The second theme of impact of the experience highlights the differences in how much participants enjoyed each condition and those features that they felt added extra value to the experience (Figure 3; for examples, see Table 3).

The subtheme enjoyability revealed that both age groups found the VR condition more enjoyable than the video condition. This is not surprising as some of them had never used a VR headset before and therefore it was a novel experience in two dimensions: a new species viewed through a new 3-D experience. In both groups, $66.7 \%$ of the participants had used VR before data collection; however, some mentioned that they had used it only once before. When asked how enjoyable the experiences were, adult participants in the VR condition remarked on how different this was to a video, and participants in the video condition highlighted the potential of videos to better convey information compared to written interpretations.

The subtheme informativeness did not show marked differences in the two conditions; however, some participants in the VR condition commented that the novel experience of the VR and the vivid visual stimulus made it less likely that they would listen to the audio information, and that had made the experience less informative. This theme emerged only with the child participants.

In the third subtheme (naturalistic view) children in both conditions highlighted that the VR and the video tools both provide a naturalistic view of the species. While the VR's immersive feature can hinder attention to information and therefore retention, VR appears to give an enhanced feeling of being 
in a natural environment with the species of interest. Adults highlighted an interesting contrast between their experiences and the zoo environment. Although children generally enjoyed the naturalistic experiences of the VR and the video, adults explicitly contrasted it with the zoo, pointing out the limitations of the zoo environment.

\section{Figure 3}

Summary of 'Impact of Experience' Theme by Responses

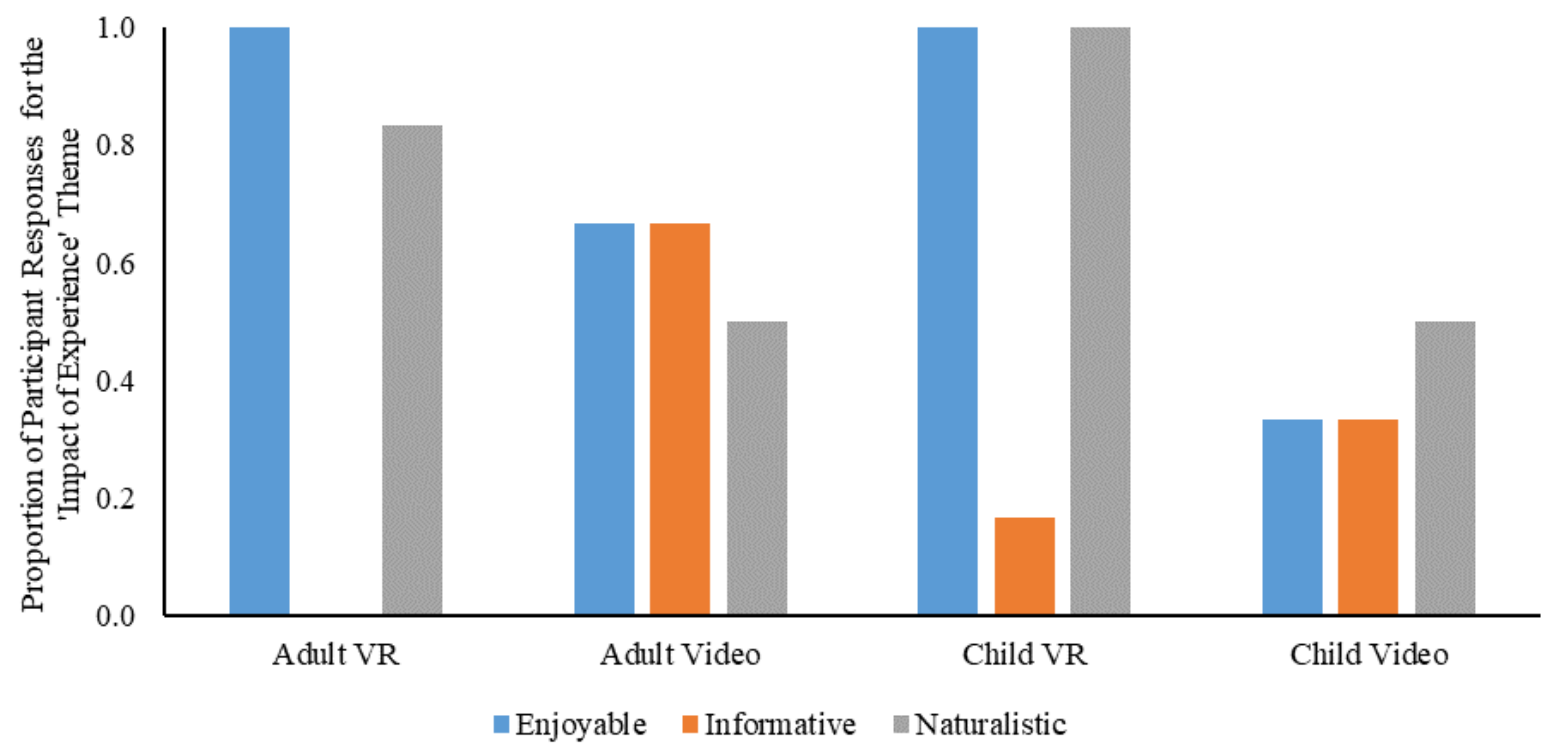

Table 3

Examples of the 'Impact of the Experience' Theme

\begin{tabular}{|c|c|c|}
\hline Subthemes & VR & Video-only \\
\hline Enjoyable & $\begin{array}{l}\text { Child } \\
\text { "...The VR. That was cool... There is just like interesting } \\
\text { things going on." } \\
\text { Adult } \\
\text { "I really did (enjoy). I think before I put it on, I didn't } \\
\text { think it would be that different from the video, but it } \\
\text { really was, I enjoyed it a lot." }\end{array}$ & $\begin{array}{l}\text { Child } \\
\text { "I am not sure it is enjoyable. But interesting." } \\
\frac{\text { Adult }}{\text { "If there's things like that, you get a lot more }} \\
\text { information about them, I think it can make the } \\
\text { visit more interesting." }\end{array}$ \\
\hline $\begin{array}{l}\text { Informative- } \\
\text { Child only }\end{array}$ & $\begin{array}{l}\text { "The VR aspect is distracting from the actual } \\
\text { information being told to me." } \\
\text { "Yeah, I thought it was very informative. It was very } \\
\text { good to be able to look around and actually see them } \\
\text { close up. I guess it seems more personal." }\end{array}$ & $\begin{array}{l}\text { "It was interesting to see what was... What we } \\
\text { were doing to make them endangered." }\end{array}$ \\
\hline Naturalistic view & $\begin{array}{l}\text { Child } \\
\text { "... with the VR you can be like in their natural habitat } \\
\text { with them and it's more." } \\
\text { Adult } \\
\text { "That was really close up that you can experience } \\
\text { wildlife, how they live instead of how it is in the zoo." }\end{array}$ & $\begin{array}{l}\text { Child } \\
\text { "They look more like natural in the video." } \\
\text { "Ydult } \\
\text { than an enclosed environment here." }\end{array}$ \\
\hline
\end{tabular}




\section{Theme Three: Purpose of the Technology}

Interviews with adults uncovered an additional theme that focuses on the purpose of the technology (for examples see Table 4). Those in the video condition remarked positively on the educational aspect of the technology and the fact that it would be more engaging for children. During interviews about the VR experience, adults pointed to the possibility of using it to make the zoo experience more interactive, apparently for both children and adults.

\section{Table 4}

Examples of the Theme 'Purpose of the Technology' in the 19+ Age Group

\begin{tabular}{l|l|l} 
Theme & VR & Video \\
\hline $\begin{array}{l}\text { Purpose of } \\
\text { technology }\end{array}$ & $\begin{array}{l}\text { "It's a bit more interactive, which is why you come to } \\
\text { the zoo in the first place." }\end{array}$ & $\begin{array}{l}\text { So it's quite good to be educational as well as fun. } \\
\text { think it is a good way to teach the young ones about them } \\
\text { (animals)." }\end{array}$
\end{tabular}

\section{Discussion}

Zoos are often seen by their visitors as leisure facilities (Ballantyne et al., 2007) and thus new experiences and engagement with novel technology can be viewed as "added attractions." We aimed to investigate whether VR is a technology that simply enhances "a day out" or whether it provides opportunities for greater engagement with a wider range of species, especially those which cannot be easily kept in zoos but are of major conservation importance. The semi-structured interviews allowed us to gain more in-depth understanding of what visitors liked about the VR experience and our exploratory work could be used as a baseline for further investigation.

We asked visitors what they thought about a VR experience in which they were introduced to African wild dogs as part of their zoo engagement for the day. The VR experience was compared to a structurally similar video presentation. Every interviewee from both age groups said that they enjoyed the VR experience while only around 50\% of the participants enjoyed the video presentation (Figure 2). Participants in the VR condition explained that the VR experience was not what they expected; one participant said they expected it to be more like a video and were pleasantly surprised how different and engaging the VR was (Table 3). Children in both conditions highlighted how informative they found the experiences. In the VR condition, children said they liked how the animals could be observed up close; this closeness seemed to be an essential part of how informative they found the experience. It is interesting to note that children in the video condition found the devastating human impact on the species more informative than being able to discover things about the species (Table 3). Both adults and children described how they enjoyed seeing the animals in their natural environment. Some participants in each condition and age group contrasted the naturalistic view that the VR or the video provided by comparison to the zoo environment.

Participants in both conditions gave accounts of how they enjoyed what they saw, but adults in the video condition remarked that videos are a good way to educate the younger generation. This differentiation was not made in the VR condition. This might suggest that older participants in the VR condition found the tool useful for educating and engaging themselves as well as children. Recalling factual information from the VR experience was, however, limited (Figure 2). VR technology might prove useful in a renewed effort to engage with visitors, providing a simultaneously educational and entertaining experience at the zoo. The entertainment value stems from the use of the novel platform, while the educational component is the content presented (Rapeepisarn et al., 2006). As previous research has established, learning opportunities at the zoo may provide long lasting benefits to visitors in terms of knowledge of specific issues and knowledge of actions aimed at protecting biodiversity (Jensen et al., 2017). Future research should aim to explore the relationship between VR based learning opportunities at 
the zoo and its long-term outcome and whether VR is primarily seen as entertainment or a tool for education.

It is possible that a difference in the average age of the adult participants, (adults in the video condition were on average 15 years older than those in the VR condition) might explain why the video condition was found to be more informative. This older population possibly found videos more reminiscent of TV-wildlife documentaries (personal observation), which are more traditionally used in education. The VR technology was a novelty for $43 \%$ of the adults in that condition. Participants who were truly immersed in the VR experience however paid little attention to the narration and expressed frustration that they could not recall information. Even though the basic structure of the narration was the same for both conditions, more information was provided and possibly absorbed in the video condition. Less audio information was provided for the VR condition as we predicted that the nature of the experience, more life-like, closer visual stimulus would balance out any missing audio information. Too much audio in an immersive experience has been shown to interfere with information retrieval (Nelson et al., 2020). Therefore, improved ways are needed to convey information in VR experiences if it is to be used for wider public education. VR experiences that are more interactive and led by the users themselves could be one solution, which would provide the means for participants to control how information is displayed, such as subtitles or audio information that they can activate during parts of the experience.

The immersive features of VR can potentially be used to enhance conservation messages as part of renewed efforts to create and maintain knowledge about the natural habitats of different species. Zoo visitors could potentially ignore knowledge about conservation, considering these problems to be happening far away from home and to exotic species that they only see in zoos (personal observation). VR is able to locate the animals and the problems that they experience into a face-to-face encounter with zoo visitors. The present study highlights that children found the VR more enjoyable than the video. If zoos aim to reconnect such a population with nature and its treasures, VR could be a powerful tool to do so.

Previous use of $360^{\circ}$ VR experiences among adults has been shown to increase engagement with issues of conservation and also to encourage donations (Nelson et al., 2020). VR is thus not only a tool for information dissemination but can also function to increase empathy among those who experience its immersive engagement with real world problems (Herrera et al., 2018; Markowitz et al., 2018). Empathy can play a major role when public opinion influences the priorities of conservation efforts and funding. Translating such an effect into the world of zoos suggests that providing VR experiences for zoo visitors could enhance visitors' connectedness to animals and nature, with consequences for future actions and investment.

In the course of the interviews, we asked participants if they could envision making any changes in their lives to help ongoing conservation efforts. Both the video and the VR experience offered simple solutions such as recycling or regular zoo visits. Even though it did not emerge as a theme, one child participant in both conditions expressed how powerless they feel. They said that changes are up to adults and they are only children, therefore they cannot do anything to help wildlife. We propose that further work should explore how children can be empowered by activities introduced via VR, from wildlife exploration through species recognition to conservation action (e.g., School strike for Climate).

We also found that visitors would be interested in discovering more animals and habitats via VR. The interviews suggested that visitors do not view VR as a replacement for seeing live animals at the zoo but as added value to their visit (e.g. " For example, see the pandas, if they are both inside sleeping, you can't see them. But with stuff like this (VR) lying around, it is a bit more interactive"). It is important to note that flexibility provided by the VR experiences might carry benefits compared to animal shows or demonstrations. Spooner et al. (2021) found that elements of animal shows that exhibited non-natural behaviors can lead to misinterpretation of the animal's behavioral adaptation and ultimately can limit the understanding of conservation messages. VR should provide added value to zoo visits by allowing direct encounters with a vast array of species and ideally in a way that clearly communicates the conservation issues of our time. 
In common with many studies in zoos (see Mellish et al., 2019), capturing an interview pool from a diverse range of ages and socio-economic backgrounds is difficult and can be a function of weather, local holidays, ease of access, entry cost and so on, especially when there are time constraints on the period available for data collection as was the case here. Additional research is required, given our small sample size, the low diversity of our participants, and a focus on only a single species of conservation concern. Zoo and aquaria visitors are also a specific group of subjects, self-selected for an interest in animals. Our use of participants from a different 'tech-savvy' environment, although all had had zoo experiences, was a function of limited numbers of school-age zoo visitors during the period of data collection. These slightly older participants may have biased the positive approaches to VR, although we found no marked difference in themes between those interviewed at the zoo or out with the zoo. These caveats aside, the relatively small number of participants $(n=24)$ was above the recommendations outlined by Braun and Clarke (2013) where convergence in themes is expected after six to eight interviews (Guest et al., 2006).

\section{Conclusion}

Given the many challenges to zoos, from Covid-19 closures to human rights judgements, the use of enhanced virtual reality simulations (Carter et al., 2020) as educational and welfare tools should be considered as a potentially valuable and welfare positive addition to the visitor experience. Our results need replication with a larger sample size from a range of zoos, with people from diverse backgrounds and including a greater range of exposure to environmental contexts, endangered species, technologies or alternative modes of conservation education (Spooner et al., 2019).

\section{Acknowledgements}

We would like to thank Brenda Lee and her team at Reality Garage (Boulder, Colorado, USA) for their kind support and the incredible VR experience. We would like to thank the students from the University of Stirling who helped with data collection and the research assistant who coded a portion of the data. We are also grateful that the University of Stirling allowed us to use the VR hardware for our research. We thank RZSS and the Learning and Discovery team for their ideas and support throughout the data collection period. We also thank those who have read and provided constructive feedback of this work.

\section{Author contributions}

Zsuzsa Lugosi designed the study with the supervision of Phyllis C. Lee. Zsuzsa Lugosi collected and analyzed the data. Zsuzsa Lugosi and Phyllis C. Lee created the manuscript collaboratively.

\section{References}

Ahn, S. J., Bostick, J., Ogle, E., Nowak, K., McGillicuddy, K., \& Bailenson, J. N. (2016). Experiencing nature: Embodying animals in immersive virtual environments increases inclusion of nature in self and involvement with nature. Journal of Computer-Mediated Communication, 21(6), 399-419. https://doi.org/10.1111/jcc4.12173

Allison, D., Wills, B., Bowman, D., Wineman, J., \& Hodges, L. F. (1997). The virtual reality gorilla exhibit. IEEE Computer Graphics and Applications, 17(6), 30-38. https://doi.org/10.1109/38.626967

Annetta, L., Mangrum, J., Holmes, S., Collazo, K., \& Cheng M. (2009). Bridging realty to virtual reality: Investigating gender effect and student engagement on learning through video game play in an elementary school classroom. International Journal of Science Education, 31(8), 1091-1113. https://doi.org/10.1080/09500690801968656 
Ballantyne, R., Packer, J., Hughes, K., \& Dierking, L. (2007). Conservation learning in wildlife tourism settings: Lessons from research in zoos and aquariums. Environmental Education Research, 13(3), 367-383. https://doi.org/10.1080/13504620701430604

Braun, V., \& Clarke, V. (2006). Using thematic analysis in psychology. Qualitative Research in Psychology, 3(2), 77-101. https://doi.org/10.1191/1478088706qp063oa

Braun, V., \& Clarke, V. (2013). Successful qualitative research: A practical guide for beginners. Sage.

Carr, N., \& Cohen, S. (2011). The public face of zoos: Images of entertainment, education and conservation. Anthrozoös, 24(2), 175-189. https://doi.org/10.2752/175303711X12998632257620

Carter, M., Webber, S., Rawson, S., Smith, W., Purdam, J., \& McLeod, E. (2020). Virtual reality in the zoo: A qualitative evaluation of a stereoscopic virtual reality video encounter with Little penguins (Eudyptula minor). Journal of Zoo and Aquarium Research, 8(4), 239-245. https://doi.org/10.19227/jzar.v8i4.500

Coe, J., \& Hoy, J. (2020). Choice, control and computers: Empowering wildlife in human care. Multimodal Technologies and Interaction, 4(92). 1-18. https://doi.org/10.3390/mti4040092

D’Cruze, N., Khan, S., Carder, G., Megson, D., Coulthard, E., Norrey, J., \& Groves, G. (2019). A global review of animal-visitor interactions in modern zoos and aquariums and their implications for wild animal welfare. Animals, 9(6). 1-20. https://doi.org/10.3390/ani9060332

Dolins, F. L., Schweller, K., \& Milne, S. (2017). Technology advancing the study of animal cognition: Using virtual reality to present virtually simulated environments to investigate nonhuman primate spatial cognition. Current Zoology, 63(1), 97-108. https://doi.org/10.1093/cz/zow121

Godinez, A. M., \& Fernandez, E. J. (2019). What is the zoo experience? How zoos impact a visitor's behaviors, perceptions and conservation efforts. Frontiers in Psychology, 10, 1746. https://doi.org/10.3389/fpsyg.2019.01746

Guest, G., Bunce, A., \& Johnson, L. (2006). How many interviews are enough? An experiment with data saturation and variability. Field Methods, 18(1), 59-82. https://doi.org/10.1177/1525822X05279903

Gusset, M., \& Dick, G. (2010). The global reach of zoos and aquariums in visitor numbers and conservation expenditures. Zoo Biology, 30(5), 566-569. https://doi.org/10.1002/zoo.20369

Herrera, F., Bailenson, J. N., Weisz, E., Ogle, E., \& Zaki J. (2018). Building long-term empathy: A large-scale comparison of traditional and virtual reality perspective-taking. PLoS ONE 13(10), e0204494. https://doi.org/10.1371/journal.pone.0204494

Jensen, E. A., Moss, A., \& Gusset, M. (2017). Quantifying long-term impact of zoo and aquarium visits on biodiversity-related learning outcomes. Zoo Biology, 36(4), 294-297. https://doi.org/10.1002/zoo.21372

Kallio, H., Pietila, A., Johnson, M., \& Kangasniemi, M. (2016). Systematic methodological review: Developing a framework for a qualitative semi-structured interview guide. Journal of Advanced Nursing, 72(12), 29542965. https://doi.org/10.1111/jan.13031

Lamb, R., Antonenko, P., Etopio, E., \& Seccia, A. (2018). Comparison of virtual reality and hands on activities in science education via functional near infrared spectroscopy. Computers \& Education, 124, 14-26 https://doi.org/10.1016/j.compedu.2018.05.014

Learmonths, M. J. (2020). Human-animal interactions in zoos: What can compassionate conservation, conservation welfare and duty of care tell us about the ethics of interacting, and avoiding unintended consequences? Animals, 10(11), 2037, https://doi.org/10.3390/ani10112037

Luebke, J. F., \& Matiasek, J. (2013). An exploratory study of zoo visitors' experiences and reactions. Zoo Biology, 32(4), 407-416. https://doi.org/10.1002/zoo.21071

Markowitz, D. M., Laha, R., Perone, B. P., Pea, R. D., \& Bailenson, J. N. (2018). Immersive virtual reality field trips facilitate learning about climate change. Frontiers in Psychology, 9, 2364. https://doi.org/10.3389/fpsyg.2018.02364

Mellish, S., Ryan, J. C., Pearson, E. L., \& Tuckey, M. R. (2019). Research methods and reporting practices in zoo and aquarium conservation-education evaluation. Conservation Biology, 33(1), 40-52. https://doi.org/10.1111/cobi.13177

Nelson, K. M., Anggraini, E., \& Schlüter, A. (2020). Virtual reality as a tool for environmental conservation and fundraising. PLoS ONE, 15(4). 1-21 https://doi.org/10.1371/journal.pone.0223631

Ota, D., Loftin, B., Saito, T., Lea, R., \& Keller, J. (1995). Virtual reality in surgical education. Computers in Biology and Medicine, 25(2), 127-137. https://doi.org/10.1016/0010-4825(94)00009-F

Rapeepisarn, K., Wong, K. W., Fung, C. C., \& Depickere, A. (2006, December 4-6). Similarities and differences between "learn through play" and "edutainment." Proceedings of the 3rd Australasian Conference on Interactive Entertainment, 28-32. https://researchrepository.murdoch.edu.au/id/eprint/993/ 
Roe, K., McConney, A., \& Mansfield, C. F. (2014). How do zoos 'talk' to their general visitors? Do visitors 'listen'? A mixed method investigation of the communication between modern zoos and their general visitors. Australian Journal of Environmental Education, 30(2), 167-186. https://doi.org/10.1017/aee.2015.1

Sherwen, S. L., \& Hemsworth, P. H. (2019). The visitor effect on zoo animals: Implications and opportunities for zoo animal welfare. Animals 9(6), 366. https://doi.org/10.3390/ani9060366

Spooner, S. L., Jensen, E. A., Tracey, L., \& Marshall, A. R. (2019). Evaluating the impacts of theatre-based wildlife and conservation education at the zoo. Environmental Education Research, 25(8), 1231-1249. https://doi.org/10.1080/13504622.2019.1569201

Spooner, S. L., Jensen, E. A., Tracey, L., \& Marshall, A. R. (2021). Evaluating the effectiveness of live animal shows at delivering information to zoo audiences. International Journal of Science Education, Part B, 11(1), 1-16. https://doi.org/10.1080/21548455.2020.1851424

Tan, S., \& Waugh, R. (2013). Use of virtual-reality in teaching and learning molecular biology. In Y. Cai (Ed.), 3D immersive and interactive learning (pp. 17-43). Springer.

WAZA (2017). Annual report. https://www.waza.org/wp-content/uploads/2019/02/2017-WAZA-AnnualReport_Final.pdf 